\title{
A Thai version of the Michigan hand questionnaire (Thai MHQ): an investigation of the psychometric properties
}

Pichitchai Atthakomol ${ }^{12^{*}} \mathbb{D}$, Worapaka Manosroi ${ }^{3}$, Saran Sanguanrungsirikul', Siraphop Punoppamas', Sirapat Benjachaya ${ }^{1}$, Siam Tongprasert ${ }^{4}$ and Tinakon Wongpakaran ${ }^{5}$

\begin{abstract}
Background: The Michigan Hand Questionnaire (MHQ) is widely used to assess the hand/wrist conditions. We translated the original version into Thai (Thai $\mathrm{MHQ}$ ) and evaluated its psychometric properties.

Methods: After receiving permission, the original MHQ was translated and cross-culturally adapted to Thai following standard guidelines. Two hundred and seventeen patients who had hand/wrist injuries or disorders were included in the study. Internal consistency was evaluated using Cronbach's alpha. Test-retest reliability was analyzed using the intraclass correlation coefficient (ICC). Spearman's rank correlation among the subscales of Thai MHQ, Thai DASH and Thai EQ-5D-5L and also confirmatory factor analysis (CFA) were used to explore construct validity. The standardized response mean (SRM) was used to evaluate the responsiveness of the Thai MHQ.

Results: All subscales showed an acceptable Cronbach's alpha (0.79-0.98). The test-retest reliability of each subscale was good (ICC $=0.83-0.95)$. In related dimensions, strong correlation was demonstrated between the Activities of daily living subscale of the Thai MHQ and the Common activities subscale in the Thai DASH $(r=0.77, P<0.0001)$. For unrelated dimensions, a weak correlation was found between the Aesthetics subscale in the Thai MHQ and the Mobility subscale in the Thai EQ-5D-5L $(r=-0.13, P=0.05)$. The Thai MHQ had strong correlation with Thai DASH $(r=-0.79, P<0.0001)$ and Thai EQ-5D-5L $(r=0.63, P<0.0001)$. CFA showed that the 6 -factor model demonstrated an acceptable fit to the data. The SRM of the Thai MHQ was 0.78 , indicating relatively large responsiveness. The MIC of Thai MHQ using distribution methods (SEM) was 5.2.
\end{abstract}

Conclusions: The Thai MHQ provides adequate internal consistency in all subscales as well as good construct validity and reliability for Thai patients and a relatively large standardized response mean at 2 months after treatment.

Keywords: Thai MHQ, Reliability, Validity, Responsiveness

\footnotetext{
* Correspondence: p.atthakomol@gmail.com

${ }^{1}$ Department of Orthopaedics, Faculty of Medicine, Chiang Mai University, Chiang Mai, Thailand

${ }^{2}$ Musculoskeletal Science and Translational Research Center, Chiang Mai University, Chiang Mai, Thailand

Full list of author information is available at the end of the article
}

C C The Author(s). 2020 Open Access This article is licensed under a Creative Commons Attribution 4.0 International License, which permits use, sharing, adaptation, distribution and reproduction in any medium or format, as long as you give appropriate credit to the original author(s) and the source, provide a link to the Creative Commons licence, and indicate if changes were made. The images or other third party material in this article are included in the article's Creative Commons licence, unless indicated otherwise in a credit line to the material. If material is not included in the article's Creative Commons licence and your intended use is not permitted by statutory regulation or exceeds the permitted use, you will need to obtain permission directly from the copyright holder. To view a copy of this licence, visit http://creativecommons.org/licenses/by/4.0/ The Creative Commons Public Domain Dedication waiver (http://creativecommons.org/publicdomain/zero/1.0/) applies to the data made available in this article, unless otherwise stated in a credit line to the data. 


\section{Background}

Hand and wrist are common areas for upper extremity injuries [1-6]. To evaluate hand/wrist function and severity in the initial stage or after treatment, both clinicians and researchers need standard tools which have high reliability, validity and the ability to detect clinically important changes overtime [7,8]. During the past two decades, patient-rated outcome measurements have increasingly been used in healthcare systems. Benefits of these instruments include that they can infer the patient's perspective on many aspects which affect outcomes, while traditional outcome measurements are assessed based on the views of clinical examiner [9-12].

The Michigan Hand Outcomes Questionnaire (MHQ) is one of the widely used patient-rated outcome measurement instruments for patients with hand disorders. This questionnaire is the subjective assessment for musculoskeletal, neurological or nonspecific pathology which providing the ordinal data type according to The World Health Organization International Classification on Functioning Disability and Health (WHO ICF) summary [13]. The original version was developed in 1998 by Chung et al. [10]. Among the benefits of this instrument are its specificity to hand/wrist injuries or disorders, the capacity to evaluate impairment both individually for each hand as well as for both hands together and the ability to assess more aspects including overall hand function, activities of daily living, pain, work performance, satisfaction and specially in aesthetic compared to Disabilities of Arm, Shoulder and Hand (DASH) questionnaire $[10,11,14]$. Previous studies have also reported that the MHQ was more responsive than DASH in patients with traumatic hand injury, carpal tunnel syndrome or wrist pain $[15,16]$.

Evaluations of psychometric properties of the MHQ have documented high internal consistency and testretest reliability [10, 14, 17-19]. Furthermore, this tool has been proven to be valid and has demonstrated a high standardized response mean (SRM) in many types of hand/wrist injuries and disorders [10, 14, 18-22]. The MHQ has been translated and cross-culturally adapted into many languages including Turkish [23], Brazilian [24], Korean [25], Japanese [26], German [27], Persian [28], Polish [29], French [30], Finnish [31] and Thai [32].

Presently, what is lacking is a hand/wrist outcome measurement which is reliable, valid and responsive specifically for Thai patients who have hand/wrist injuries or disorders. Although a Thai version of MHQ has recently been reported by Dhippayom et al., that version has some limitations. The study was conducted with a small sample size (30 patients) and demonstrated a relatively low statistical power (0.51). Additionally, factor analysis and responsiveness evaluations have not been reported [32].
The aims of this study were to create a Thai version of the original $\mathrm{MHQ}$, including translation and crosscultural adaptation, and to investigate the psychometric properties of the Thai version including reliability, validity and responsiveness.

\section{Methods}

The first of two stages in this study was the translation and cross-cultural adaptation of the original MHQ to create a Thai version. The second step was to explore the psychometric properties of the Thai MHQ, including reliability, validity and responsiveness. We hypothesized that the Thai version could maintain the reliability, validity and responsiveness of other versions of MHQ. This observational study was approved by the local institutional research ethics committee.

\section{The MHQ questionnaire}

The Michigan Hand Outcomes Questionnaire (MHQ) consists of specific questions in 6 subscales including overall hand function (5 items each for left and right hand), activities of daily living (5 items each for left and right hand, 7 items for both hands); work performance (5 items); pain (5 items each for left and right hand); aesthetics (4 items each for left and right hand); and satisfaction with hand function (6 duplicate items each for left and right hand) [10]. The reliability, validity, and responsiveness of the MHQ has been investigated for many conditions of hand/wrist disorders and has been translated into many languages $[10,14-16,19-25,27-$ 32]. Raw scores are converted to scores with a range of 0 to 100 . For the Pain subscale, higher scores indicate more pain. For the other subscales, higher scores indicate better hand performance.

\section{Translation and cross-cultural adaptation}

The authors requested permission from Chung et al. to translate the original version into Thai. Translation and cross-cultural adaptation was performed following the recommendations of Beaton et al. which consist of 5 stages as described below [33].

Stage 1. Forward translation. Two bilingual translators (a Thai medical student and an academic English language instructor) independently translated the original MHQ into Thai versions (T1 and T2) [10]. Stage 2. Synthesis. The two translators discussed differences point by point and created a synthesis of the $\mathrm{T} 1$ and $\mathrm{T} 2$ versions (T-12). The differences were also discussed with an Orthopaedic hand specialist to arrive at a consensus.

Stage 3. Back translation. The T-12 version was back translated into English (BT1 and BT2 versions) by two bilingual English/Thai speakers (English language 
lecturers) to ensure that the concept of the original version was maintained.

Stage 4. Review by an expert committee on hand surgery and measurement development. An expert committee, composed of one hand surgeon, one rehabilitation specialist, one psychiatrist and two linguistics experts, reviewed and consolidated the prefinal version of Thai MHQ from all the translated versions (T1, T2, T12, BT1, BT2).

Stage 5. Field testing of the pre-final version. Field testing was conducted with 15 healthy volunteers and 15 patients who had hand/wrist injuries. All were native Thai speakers who were fluent in reading, writing and understanding the Thai language. They were requested to examine all instructions and items for item-objective congruence (IOC) and to provide suggestions. If any item demonstrated an IOC value less than 0.5 , that item was reconstructed and reevaluated until the IOC value reached at least 0.5 . Finally, the pre-final version of the Thai MHQ was translated back into English and sent to Chung et al. for approval.

\section{Psychometric testing of the Thai MHQ}

Internal consistency, construct validity, factor analysis, test-retest reliability and responsiveness of Thai MHQ were evaluated in Thai patients who were enrolled prospectively at the Hand Outpatient Clinic of Academic University Hospital from December 2018 to December 2019. Inclusion criteria were patients who had hand/wrist musculoskeletal disorders, used Thai as their first language and had the ability to read and understand Thai, age between 15 and 70 years and had the ability to complete the questionnaire without major assistance. Patients who had a musculoskeletal disorder above wrist level, an active cerebral disorder or communication problems were excluded. Since there were many types of hand and wrist injuries or disorders, the treatments might include both conservative and operative treatments. The follow-up schedule to evaluate responsiveness was at least 4 weeks after treatment depending on the diagnosis of each patient. This study adhered to the COnsensus-based Standards for the selection of health Measurement Instruments (COSMIN) checklist [34].

After giving informed consent, patients were enrolled in study. Patient demographic data recorded include age, sex, dominant hand, injured hand, diagnosis and time taken to complete the questionnaire.

\section{Internal consistency}

Internal consistency is the degree of correlation between items measuring the same outcome. Cronbach's alpha was used to measure the internal consistency of each subscale and the total score of Thai MHQ. Values can range from 0 to 1 , with higher scores indicating greater interrelatedness between items. Values of 0.70 or higher are considered to be adequate [35].

\section{Test-retest reliability}

Test-retest reliability is the ability of successive measurements to obtain similar results in a stable individual. The recommended time between the initial and the repeat administration of the measurement is 1 week to avoid recall and to ensure that clinically significant change has not occurred. The Thai MHQ was administered twice with a 7day interval before treatment [36]. The intraclass correlation coefficient (ICC), which can range from 0 to 1 , was $>0.7$ indicating good reliability [36].

\section{Construct validity}

Construct validity is a measure of the association between an instrument and theoretically hypotheses concerning the concepts being measured [36, 37]. The Thai version of the disabilities of the arm, shoulder and hand questionnaire (Thai DASH) $[38,39]$ and the Thai EQ-5D-5L [4042] were used to evaluate the construct validity of the concepts being measured in this study. Correlation among the subscales of the Thai MHQ, Thai EQ-5D-5L and Thai DASH were measured using the Spearman's rank correlation coefficient $(r)$. We hypothesized that the same or related subscales should show a high correlation (Pain subscale between the Thai MHQ, the Thai DASH and the Thai EQ-5D-5L), while unrelated subscales should demonstrate a weak correlation (Aesthetics subscale in the Thai MHQ and the Pain subscale in the Thai DASH, the Aesthetics subscale in the Thai MHQ and the Mobility subscale in the Thai EQ-5D-5L) and the Thai MHQ should be strong correlated to the Thai DASH. The level of correlation was rated as low $(r<0.3)$, moderate $(0.3 \leq$ $\mathrm{r} \leq 0.6)$, or strong $(r>0.6)$ [43].

\section{Thai DASH}

The Thai DASH questionnaire consists of 30 selfreported items to assess symptoms and disability status. It also contains 2 optional modules, a Work and sports subscale and a Performing arts subscale [11]. The Thai version was translated by Tongprasert et al. and its psychometric properties were tested by Buntragulpoontawee et al. [38, 39]. The DASH questionnaire consists of 5 subscales: Common activities, Self-care activities, Pain symptoms, Other symptoms including numbness, joint stiffness, weakness, and sleep problems and Psychological effects. Scores range from 0 to 100 , with higher scores representing greater disability.

\section{Thai EQ-5D-5L}

The EQ-5D-5L is a two-part outcome measurement extensively used to evaluate health status $[44,45]$. The first 
part consists of 5 subscales: Mobility, Self-care, Usual activities, Pain/discomfort and Anxiety/depression. Each subscale has five levels of severity ranging from no problems to extreme problems. The second part uses numeric scales to evaluate general health condition with scores ranging from 0 to 100 , where higher scores indicate better health. The original version was translated into Thai and its psychometric properties have been evaluated [40-42]. The index value of Thai EQ-5D-5L in each patient was calculated from EQ-5D-5L Crosswalk Index Value Calculator which was available for the following countries: Denmark, France, Germany, Japan, the Netherlands, Spain, Thailand, UK, US and Zimbabwe (https://euroqol.org/eq-5d-instruments/eq-5d-5l-about/ valuation-standard-value-sets/crosswalk-index-value-calculator/). We used the Thai index which ranged from 0.452 to 1.000 [46].

Construct validity of the Thai MHQ was also investigated using confirmatory factor analysis (CFA) to evaluate the nature of and relations between latent constructs. Maximum likelihood estimation was used to evaluate the parameters. Both unidimensional construct and 6-factor-model of the Thai MHQ were analyzed. Indexes used for evaluating goodness of fit included a comparative fit index (CFI) of $\geq 0.95$, a non-normed fit index (NFI) or Tucker-Lewis Index (TLI) $\geq 0.9$. A rootmean-square error of approximation (RMSEA) $\leq 0.6$ $(0.08)$ was considered an acceptable fit $[47,48]$ and a $c^{2} /$ $d f<3[47,48]$. Modification indices were used after initial analysis, and error term correlation was used when indicated [49].

\section{Responsiveness}

Responsiveness is the ability of a measurement to detect clinically significant changes over time [36]. Responsiveness of the Thai MHQ was evaluated by comparing the scores at baseline and at follow-up periods using the standardized response mean (SRM) and effect size (ES). SRM was calculated as the observed mean change divided by the standard deviation of the observed change while ES was evaluated as the observed mean change divided by the standard deviation of the baseline scores. SRM is the preferred value to compare paired data measurements at different time points for the same patient. We hypothesized that Thai MHQ should provide moderate to large responsiveness. SRM and ES values of 0.8, 0.5, and 0.2 were considered to be large, moderate, and small, respectively $[21,50]$. The minimal important change (MIC) of Thai MHQ was evaluated using distribution methods and reported as the standard error measurement ( SEM $=$ Standard deviation $* \sqrt{1-\text { reliability }})$ [51]. The smallest detectable change (SDC) was analyzed as 1.96 $\times \sqrt{2} \times \operatorname{SEM}[52]$.

\section{Floor or ceiling effects}

Floor or ceiling effects were considered to be present if more than $15 \%$ of patients reported the lowest or highest possible scores [53]. If floor or ceiling effects are present, it means extreme items are missing in the lower or upper end of the scale, indicating limited content validity. Patients with the lowest or highest possible score cannot be distinguished from each other, so reliability is limited. Additionally, responsiveness is reduced since changes cannot be evaluated in these patients [36].

\section{Statistical analysis}

For demographic data, categorical variables are reported as frequencies and percentages. Continuous variables are reported as means and standard deviations. Statistical significance was set at $P<0.05$. In multiple comparisons, the $P$-value was adjusted using Bonferroni's method. Following on Mundfrom et al. regarding levels of communality the ratio of the number of variables to the number of factors indicated, a minimum sample size of 200 patients was sufficient for factor analysis in this study with 37 variables and 5 factors [54]. The present study included 217 participants in the analysis.

\section{Results}

\section{Translation and cross-cultural adaptation}

Minor cross-cultural adaptations were modified in the activities of daily living subscale. The item "Eat with a knife/fork" was changed to "Eat with spoon and fork". Other adaptations were made in the patient characteristics (information) section. The items "What is your ethnic background?", "What is your racial background?" and "How long after your surgery did you return to the job you were doing before your injury" were removed. The range of family income was changed in the item "What is your approximate family income". During field testing, 30 volunteers (15 healthy volunteers and 15 patients) completed the pre-final version. All items had an IOC $>0.5$, an acceptable level. The final Thai version was approved by Michigan Center for Hand Outcomes and Innovation Research.

Demographic data are shown in Table 1. Two hundred and seventeen hand/wrist injury or disorder patients were recruited. No floor or ceiling effects were found in the total scores of the Thai MHQ. The average time 114 patients took to complete the questionnaire was 12.11 min.

\section{Internal consistency and test-retest reliability}

The internal consistency of the Thai MHQ was assessed with 217 patients (Table 2). All subscales had adequate internal consistency. Most subscales (Overall hand function, Activities of daily living, Work performance, Pain, and Satisfaction with hand function demonstrated high 
Table 1 Demographic data of patients $(n=217)$

\begin{tabular}{ll}
\hline Age (years); mean \pm SD & $47 \pm 17$ \\
Female; n (\%) & $143(66)$ \\
Right-hand dominant; $n$ (\%) & $191(88)$ \\
Injured hand; n (\%) & \\
Right & $93(43)$ \\
Left & $97(45)$ \\
Both & $27(12)$ \\
Diagnosis; $n(\%)$ & \\
Joint stiffness & $7(3)$ \\
Nerve injury & $2(1)$ \\
Wrist fracture & $39(18)$ \\
Tendon entrapment & $56(26)$ \\
Compound fracture & $1(0.5)$ \\
Joint arthritis & $13(6)$ \\
Nerve entrapment & $35(16)$ \\
Tumor & $17(8)$ \\
Tendon injury & $13(6)$ \\
Hand infection & $4(2)$ \\
Ligament injury & $6(3)$ \\
Calcific tendinitis & $1(0.5)$ \\
Joint dislocation & $7(3)$ \\
Hand fracture & $8(4)$ \\
Malunion & $1(0.5)$ \\
Foft tissue injury & $4(2)$ \\
\hline SD Standard & $3(1)$ \\
\hline
\end{tabular}

SD Standard deviation

Cronbach's alpha values ranging from 0.94 to 0.98 , while the Aesthetics subscale presented slightly lower Cronbach's alpha values ( 0.79 for right, 0.80 for Left). After excluding patients who were not followed up after 1 week and patients who could not complete all the items, test-retest reliability was performed with 72 patients. The results showed all subscales had good reliability with ICC values between 0.83 and 0.95 (Table 3).

\section{Construct validity}

Evaluation of the construct validity of the Thai MHQ was conducted with 217 patients. The correlation of subscales for the Thai MHQ, the Thai DASH and the Thai EQ-5D$5 \mathrm{~L}$ was compared (Table 4). In related dimensions, the assessment of the Pain subscale between the Thai MHQ, the Thai DASH and the Thai EQ-5D-5L found a relatively strong correlation between the Thai MHQ and the Thai DASH $(r=0.58, P<0.0001)$ as well as between the Thai MHQ and the Thai EQ-5D-5L $(r=0.59, P<0.0001)$. A strong correlation $(r=0.77, P<0.0001)$ was demonstrated between the Activities of daily living in the Thai MHQ and the Common activities in the Thai DASH, indicating
Table 2 Cronbach's alpha for each subscale in the Thai MHQ $(n=217)$

\begin{tabular}{ll}
\hline Subscale & Cronbach's Alpha \\
\hline I. Overall hand function & \\
Right hand & 0.94 \\
Left hand & 0.94 \\
2. Activities of daily living & \\
Right hand & 0.97 \\
Left hand & 0.97 \\
Both hands & 0.96 \\
3. Work performance & 0.94 \\
4. Pain & \\
Right hand & 0.97 \\
Left hand & 0.98 \\
5. Aesthetics & \\
Right hand & 0.79 \\
Left hand & 0.80 \\
6. Satisfaction with hand function & \\
Right hand & 0.95 \\
Left hand & 0.96 \\
\hline$H Q$ Michigan Hand Questionnaire &
\end{tabular}

MHQ Michigan Hand Questionnaire

convergent validity. Among unrelated dimensions, there were the weak negative correlations between the Aesthetics subscale in the Thai MHQ and the Pain subscale in the Thai DASH $(r=-0.20, P=0.003)$ and also between the Aesthetics subscale in the Thai MHQ and the Mobility subscale in the Thai EQ-5D-5L $(r=-0.13, P=0.05)$ indicating discriminant validity. There were the strong correlations between Thai MHQ and Thai DASH $(r=-0.79$, $P<0.0001)$ and between Thai MHQ and Thai EQ-5D-5L $(r=0.63, P<0.0001)$.

\section{CFA}

The unidimensional model showed an acceptable fit to the data with a CFI of 0.985, TLI of 0.983, RMSEA of 0.080 (90\%C.I., 0.073-0.087), SRMR of 0.067, and a $\chi^{2}=$ $891.834, d f=374(p<0.001)$. However, the 6-factor solution fitted the data best with the following statistics: CFI was 0.995 , TLI was 0.994, RMSEA was 0.047 (90\%C.I., $0.039-0.055)$, SRMR was 0.041 , and a $\chi^{2}=570.062, d f=$ $385(p<0.001)$. The fit statistics for all models were based on the fact that the error terms of the indicators within the same subscale were correlated.

\section{Responsiveness}

Fifty patients continued with followed-up after receiving initial treatment and completed all items in the Thai MHQ questionnaire both before treatment and at follow-up. The mean time to follow-up was 52 days. The three most common treatments were steroid injection (32\%), surgical fixation (26\%) and surgical release (20\%). 
Table 3 Test-retest reliability of the Thai MHQ $(n=72)$

\begin{tabular}{llllll}
\hline Subscale & Baseline & Retest & ICC & & \multicolumn{2}{l}{$95 \%$ confidence Interval } \\
\cline { 4 - 6 } & Mean \pm SD & Mean \pm SD & & & Lower bound \\
\hline Overall hand function & $64.90 \pm 19.79$ & $65.17 \pm 23.07$ & 0.93 & 0.88 & 0.95 \\
Activities of daily living & $75.36 \pm 23.42$ & $74.72 \pm 25.82$ & 0.87 & 0.79 & 0.92 \\
Work performance & $54.58 \pm 30.10$ & $58.06 \pm 32.18$ & 0.83 & 0.73 & 0.90 \\
Pain & $40.03 \pm 28.86$ & $36.18 \pm 29.31$ & 0.95 & 0.92 & 0.97 \\
Aesthetics & $60.59 \pm 25.71$ & $61.20 \pm 24.23$ & 0.87 & 0.79 & 0.92 \\
Satisfaction with hand function & $55.82 \pm 26.36$ & $55.84 \pm 26.45$ & 0.90 & 0.84 & 0.94 \\
Thai MHQ & $61.87 \pm 21.08$ & $63.13 \pm 22.62$ & 0.95 & 0.91 & 0.97
\end{tabular}

The distribution of patients based on the diagnosis was 17 wrist fracture (23.6\%), 4 hand fracture (5.6\%), 16 tendon entrapment (22.2\%), 7 joint arthritis (9.7\%), 11 nerve entrapment (15.3\%), 5 ligament injury (6.9\%), 8 tendon injury (11.1\%), 1 malunion (1.4\%) and 3 tumor $(4.2 \%)$

ICC Intraclass correlation coefficient, MHQ Michigan Hand Questionnaire, SD Standard deviation

The SRM and ES of the Thai MHQ were 0.78 and 0.69 respectively indicating relatively large responsiveness (Table 5). SRM and ES of Thai MHQ based on each treatment were demonstrated in Table 6. The MIC of Thai MHQ using distribution methods (SEM) was 5.2 while the SDC was 14.4.

\section{Discussion}

In the process of translation and cross-cultural adaptation, previous studies have demonstrated no major linguistic or cultural discrepancies [23-26, 28-32, 5557]. In the Thai MHQ, a minor change was made in the item "Eat with a knife/fork" to be "Eat with spoon and fork" because most Thai people use a spoon as the primary eating utensil while a fork is used to manipulate the food. This is in concordance with the Korean and Japanese versions which had specific cultural eating modifications. Koreans use a spoon and chopsticks, while Japanese eat a meal with chopsticks and a rice bowl $[25,26]$. However, the previous Thai version still

Table 4 Spearman's correlation for each subscale among the Thai MHQ, Thai DASH and Thai EQ-5D-5L $(n=217)$

\begin{tabular}{|c|c|c|c|c|c|c|}
\hline \multicolumn{7}{|l|}{ (4A) Thai DASH } \\
\hline Thai MHQ & $\begin{array}{l}\text { Common } \\
\text { activities }\end{array}$ & $\begin{array}{l}\text { Self-care } \\
\text { activities }\end{array}$ & Pain & $\begin{array}{l}\text { Other } \\
\text { symptoms }\end{array}$ & $\begin{array}{l}\text { Psychological } \\
\text { effects }\end{array}$ & $\begin{array}{l}\text { Total } \\
\text { score }\end{array}$ \\
\hline Overall hand function & $-0.58^{*}$ & $-0.53^{*}$ & $-0.40^{*}$ & $-0.33^{*}$ & $-0.33^{*}$ & $-0.59^{*}$ \\
\hline Activities of daily living & $-0.77^{*}$ & $-0.72^{*}$ & $-0.49^{*}$ & $-0.41^{*}$ & $-0.38^{*}$ & $-0.78^{*}$ \\
\hline Work performance & $-0.58^{*}$ & $-0.49^{*}$ & $-0.44^{*}$ & $-0.35^{*}$ & $-0.32^{*}$ & $-0.58^{*}$ \\
\hline Pain & $0.57^{*}$ & $0.52^{*}$ & $0.58^{*}$ & $0.54^{*}$ & $0.43^{*}$ & $0.62^{*}$ \\
\hline Aesthetics & $-0.38^{*}$ & $-0.33^{*}$ & -0.20 & $-0.32^{*}$ & $-0.37^{*}$ & $-0.40^{*}$ \\
\hline $\begin{array}{l}\text { Satisfaction with hand } \\
\text { function }\end{array}$ & $-0.59^{*}$ & $-0.50^{*}$ & $-0.51^{*}$ & $-0.47^{*}$ & $-0.37^{*}$ & $-0.62^{*}$ \\
\hline Total score & $-0.77^{*}$ & $-0.68^{*}$ & $-0.58^{*}$ & $-0.52^{*}$ & $-0.51^{*}$ & $-0.79^{*}$ \\
\hline \multicolumn{7}{|l|}{ (4B) Thai EQ-5D-5L } \\
\hline Thai MHQ & Mobility & Usual activities & $\begin{array}{l}\text { Self-care } \\
\text { activities }\end{array}$ & Pain & Anxiety/Depression & $\begin{array}{l}\text { Total } \\
\text { score }\end{array}$ \\
\hline Overall hand function & -0.12 & $-0.44^{*}$ & $-0.37^{*}$ & $-0.43^{*}$ & -0.20 & $0.45^{*}$ \\
\hline Activities of daily living & -0.19 & $-0.53^{*}$ & $-0.55^{*}$ & $-0.50^{*}$ & $-0.33^{*}$ & $0.60^{*}$ \\
\hline Work performance & -0.15 & $-0.47^{*}$ & $-0.33^{*}$ & $-0.41^{*}$ & -0.25 & $0.43^{*}$ \\
\hline Pain & 0.11 & $0.48^{*}$ & $0.35^{*}$ & $0.59^{*}$ & $0.33^{*}$ & $-0.51^{*}$ \\
\hline Aesthetics & -0.13 & $-0.30^{*}$ & $-0.31^{*}$ & $-0.28^{*}$ & $-0.30^{*}$ & $0.36^{*}$ \\
\hline $\begin{array}{l}\text { Satisfaction with } \\
\text { hand function }\end{array}$ & -0.09 & $-0.50^{*}$ & $-0.34^{*}$ & $-0.53^{*}$ & $-0.38^{*}$ & $0.48^{*}$ \\
\hline Total score & -0.17 & $-0.61^{*}$ & $-0.50^{*}$ & $-0.59^{*}$ & $-0.40^{*}$ & $0.63^{*}$ \\
\hline
\end{tabular}

*Statistically significant $(p<0.0025)$ adjusted for multiple comparison using Bonferroni's method DASH Disabilities of Arm, Shoulder and Hand, MHQ Michigan Hand Questionnaire 
Table 5 Standardized response mean (SRM) and effect size (ES) of each questionnaire $(n=50)$

\begin{tabular}{llllllc}
\hline & $\begin{array}{l}\text { Baseline } \\
\text { Mean } \pm \text { SD }\end{array}$ & Follow-up & Mean difference & SD of change & SD of baseline & SRM \\
\hline Thai MHQ & $52.12 \pm 19.91$ & $65.93 \pm 21.03$ & -13.81 & 17.63 & 19.91 & -0.78 \\
Thai DASH & $53.21 \pm 17.17$ & $40.49 \pm 17.11$ & 12.72 & 15.04 & 17.17 & 0.69 \\
\hline Time to for & & & & & 0.85 & 0.74 \\
\hline
\end{tabular}

Time to follow-up $=52 \pm 25$ days

DASH Disabilities of Arm, Shoulder and Hand, MHQ Michigan Hand Questionnaire, ES Effect size, SD Standard deviation, SRM Standardized response mean

used "Eat with a knife and fork" as the original English version [32]. Another different item between the current and the previous Thai versions was one of the items to evaluate the ability to do your routine work. This version used "How often did you have to reduce your work quality due to problems with your hands/wrists?" while the previous version provided the meaning as "How often did you have to reduce the steps of working in order to do your work easily due to problems with your hands/ wrists?". In the information part, both Thai versions removed the items which involved ethnic or racial background since the majority of the population in Thailand identify themselves as Thai. The range of income was also changed in both Thai versions. However, the previous Thai version added more information in medical expense reimbursement plan [32].

In the evaluation of internal consistency, most subscales of The Thai MHQ had Cronbach alpha values higher than 0.8 (range 0.94 to 0.98 ), although the Aesthetics subscale was slightly lower ( 0.79 for right and 0.80 for left). The internal consistency of this subscale is comparable to the Korean $(0.79,0.80)$, Turkish $(0.76$, $0.79)$, Canadian French $(0.83,0.79)$ and previous Thai versions $(0.48)[23,25,32,58]$. The reason for the lower values for the Aesthetics subscale could be that the first item of this subscale is positive (satisfaction with appearance) while the other items are negative, i.e., level of discomfort, depression and feeling that appearance interfered with normal social activities. Nevertheless, the original and other versions have demonstrated high internal consistency (Cronbach alpha values $=0.81-0.97$ ) $[10,24,26,31,57]$.

Exploration of the test-retest reliability of the Thai MHQ showed good to excellent reliability in all subscales $(\mathrm{ICC}=0.83-0.95)$, results comparable to the original MHQ and other versions (ICC range 0.73 to $0.99)[10,23-25,28,29,32,55,57,58]$. Only the Japanese version showed a slightly lower ICC $(0.68)$ in the left Aesthetics subscales because the majority of the cohort had no injury to the left hand [26]. The Finnish version similarly presented a low ICC (0.66) in the left Aesthetics subscales; the authors suggested the first item might have led to patients' misunderstanding and then giving contradictory answers as described in the previous paragraph [31].

Construct validity of Thai MHQ was analyzed using 2 methods: correlation of each of the subscales for common outcome measurements (Thai DASH, Thai EQ-5D$5 \mathrm{~L}$ ) and exploratory factor analysis (EFA). In comparing subscales between the Thai MHQ and other instruments, a strong correlation was found between the Activities of daily living subscale in the Thai MHQ and the Common activities subscale in the Thai DASH $(r=-$ 0.77). This correlation could be due to the similarity of questions in both subscales. Among unrelated subscales, a weak correlation was revealed when comparing each subscale of the Thai MHQ and the Mobility subscale of the Thai EQ-5D-5L $(r<0.3)$ (Table 4). These results are in concordance with our hypotheses described in the Methods section. Although there were the specific subscales in the Thai EQ-5D-5L (Mobility) and the Thai MHQ (Aesthetics). We still found the moderate to strong correlations between other subscales of the Thai MHQ and the Thai EQ-5D-5L. Therefore, the total score of the Thai MHQ and the Thai EQ-5D-5L demonstrated the strong correlation (Table 4).

Our CFA findings were consistent with the original version, supporting the 6 hypothesized model [10]. However, the unidimensional model also showed acceptable

Table 6 Standardized response mean (SRM) and effect size (ES) of Thai MHQ based on each treatment $(n=50)$

\begin{tabular}{|c|c|c|c|c|c|c|}
\hline $\begin{array}{l}\text { Treatment } \\
\mathrm{n}(\%)\end{array}$ & $\begin{array}{l}\text { Time to follow-up } \\
\text { Mean (days) } \pm S D\end{array}$ & Mean difference & SD of change & SD of baseline & SRM & ES \\
\hline Surgical fixation = $13(26 \%)$ & $81 \pm 17$ & -18.58 & 22.68 & 23.63 & -0.82 & -0.79 \\
\hline Steroid injection = $15(32 \%)$ & $39 \pm 14$ & -10.87 & 17.15 & 13.11 & -0.63 & -0.83 \\
\hline Surgical release $=11(20 \%)$ & $32 \pm 13$ & -12.25 & 13.18 & 12.12 & -0.92 & -1.01 \\
\hline Immobilization with splint $=5(10 \%)$ & $50 \pm 16$ & -17.64 & 18.93 & 24.04 & -0.93 & -0.73 \\
\hline Surgical repair = $6(12 \%)$ & $61 \pm 28$ & -10.47 & 15.28 & 30.61 & -0.69 & -0.34 \\
\hline
\end{tabular}

MHQ Michigan Hand Questionnaire, ES Effect size, SD Standard deviation, SRM Standardized response mean 
fit indicating that the sum score of the Thai MHQ can be used to represent the overall function of the hand. In addition, our CFA results support a previous study that found the Aesthetics subscale had a weak correlation with other subscales. The fit statistics of the models were much improved when the Aesthetics subscale was removed [59].

The responsiveness of the Thai MHQ demonstrated a relatively large standardized response mean $(\mathrm{SRM}=$ 0.78) which was slightly lower than the SRM of the Thai DASH for the same cohort (0.85) (Table 5). This result might be due to the more subscale in Thai MHQ (Aesthetics) compared to Thai DASH. The level of responsiveness varied with the type of disorder, the type of treatment and the follow-up period (Table 6). As a result, the responsiveness of each version varied. The original version demonstrated a large SRM (0.8) in patients who were diagnosed with carpal tunnel syndrome and who underwent surgical release with a 6-month postoperative follow-up [22]. The Dutch version had a moderate SRM $(-0.72)$ with 28 rheumatoid arthritis patients and a 3-month followup; the majority of those patients received conservative treatment [56]. The Dutch version was also used to evaluate patients with systemic sclerosis. That evaluation found a moderate SRM $(-0.74)$ with 25 patients who received a multidisciplinary team care program and a 12-week follow-up [60]. The German MHQ had an SRM of 1.7 in 35 patients with trapeziometacarpal osteoarthritis who underwent surgical treatment and had a 1-year follow-up [55]. The SRM of the Korean version for each subscale was moderate to large $(0.6-1)$ in 37 carpal tunnel syndrome patients who were evaluated at 6 months after surgery [61]. The MIC values could be interpreted based on specific diagnoses, treatments and also methodologic approaches [51]. The previous literatures reported MIC of MHQ ranged from 4.9 to 23 [14, 51].

There are some limitations in the present study. First, responsiveness to treatment for each diagnosis was not included because our aim was to focus on generalized hand/wrist injuries or disorders. Further studies could be conducted to evaluate the responsiveness with specific diagnoses, treatments and follow-up periods. Second, in the test-retest reliability and responsiveness assessments, patients who were not followed up or who did not complete the entire questionnaire were excluded, although the number of patients remaining was still comparable to previous studies [23-26, 28, 29, 31, 32, 55, 57, 58]. Finally, the Thai MHQ should be further evaluated according to item response theory, e.g., the Rasch measurement model, to provide additional information on both persons and item calibration.

\section{Conclusions}

The Thai MHQ provides adequate internal consistency in all subscales as well as good construct validity and reliability for assessing Thai patients with wrist/hand injuries or disorders and provides a relatively large standardized response mean at 2 months after treatment. The Thai MHQ is one of the standard patient-rated outcome measurements available for clinicians and researchers to use in evaluating symptoms and functions of the hand/wrist in both clinical healthcare and in medical research.

\section{Abbreviations \\ CFA: Confirmatory factor analysis; CFI: Comparative fit index; COSMIN: COnsensus-based Standards for the selection of health Measurement Instruments; DASH: Disabilities of Arm, Shoulder and Hand; ES: Effect size; ICC: Intraclass correlation coefficient; MIC: Minimal important change; MHQ: Michigan Hand Questionnaire; NFI: Non-normed fit index; $r$ : Spearman's rank correlation coefficient; RMSEA: Root-mean-square error of approximation; SDC: Smallest detectable change; SEM: Standard error measurement; SRM: Standardized response mean; STROBE: Strengthening the Reporting of Observational Studies in Epidemiology; TLI: Tucker-Lewis Index; WHO ICF: World Health Organization International Classification on Functioning Disability and Health}

\section{Acknowledgements}

This study was supported by Faculty of Medicine, Chiang Mai University, Chiang Mai, Thailand. The authors are grateful to our expert committee: Assoc. Prof. Somporn Varnado; G. Lamar Robert, PhD; Assoc. Prof. Chongchit Sripun Robert, PhD; and Miss Kamonwan Sangseekaew and to G. Lamar Robert, PhD for reviewing the manuscript.

\section{Authors' contributions}

PA initiated study conception and design. PA, SS, SP and SB performed the data collection and acquisition of data. PA, WM and TW performed the data analysis. PA, WM, ST and TW interpreted the data. PA, WM and TW wrote the manuscript. PA, WM, ST and TW edited the manuscript. PA had a role in critical revision. All authors have read and approved the manuscript.

\section{Funding}

No specific grant was received from any funding agency in the public, commercial, or not-for-profit sectors.

\section{Availability of data and materials}

The datasets used and/or analyzed during the current study are available from the corresponding author on reasonable request.

\section{Ethics approval}

This study was approved by Research Ethics Committee 4, Faculty of Medicine, Chiang Mai University. All procedures were conducted in accordance with the ethical standards of the responsible committees on human experimentation (institutional and national) and with the Helsinki Declaration of 1975, as revised in 2008. Written informed consent was obtained from all individual participants included in the study.

\section{Consent for publication \\ Not Applicable.}

\section{Competing interests}

The authors declare that they have no competing interests.

\section{Author details}

${ }^{1}$ Department of Orthopaedics, Faculty of Medicine, Chiang Mai University, Chiang Mai, Thailand. ${ }^{2}$ Musculoskeletal Science and Translational Research Center, Chiang Mai University, Chiang Mai, Thailand. ${ }^{3}$ Division of

Endocrinology, Department of Internal Medicine, Faculty of Medicine, Chiang Mai University, Chiang Mai, Thailand. ${ }^{4}$ Department of Rehabilitation Medicine, Faculty of Medicine, Chiang Mai University, Chiang Mai, Thailand. 
${ }^{5}$ Department of Psychiatry, Faculty of Medicine, Chiang Mai University, Chiang Mai, Thailand.

\section{Received: 27 June 2020 Accepted: 28 August 2020}

Published online: 22 September 2020

\section{References}

1. Ootes D, Lambers KT, Ring DC. The epidemiology of upper extremity injuries presenting to the emergency department in the United States. Hand (N Y). 2012;7(1):18-22.

2. Van Tassel DC, Owens BD, Wolf JM. Incidence estimates and demographics of scaphoid fracture in the U.S. population. J Hand Surg Am. 2010;35(8): 1242-5.

3. Feehan LM, Sheps SB. Incidence and demographics of hand fractures in British Columbia, Canada: a population-based study. J Hand Surg Am. 2006; 31(7):1068-74

4. Singer AJ, Thode HC Jr, Hollander JE. National trends in ED lacerations between 1992 and 2002. Am J Emerg Med. 2006;24(2):183-8.

5. Larsen CF, Mulder S, Johansen AM, Stam C. The epidemiology of hand injuries in the Netherlands and Denmark. Eur J Epidemiol. 2004;19(4):323-7.

6. Ferree S, van der Vliet QMJ, Nawijn F, Bhashyam AR, Houwert RM, Leenen $\mathrm{LPH}$, et al. Epidemiology of distal radius fractures in polytrauma patients and the influence of high traumatic energy transfer. Injury. 2018;49(3):630-5.

7. Smith MV, Calfee RP, Baumgarten KM, Brophy RH, Wright RW. Upper extremity-specific measures of disability and outcomes in orthopaedic surgery. J Bone Joint Surg Am. 2012:94(3):277-85.

8. Wright RW, Baumgarten KM. Shoulder outcomes measures. J Am Acad Orthop Surg. 2010;18(7):436-44

9. Levine DW, Simmons BP, Koris MJ, Daltroy LH, Hohl GG, Fossel AH, et al. A self-administered questionnaire for the assessment of severity of symptoms and functional status in carpal tunnel syndrome. J Bone Joint Surg Am. 1993;75(11):1585-92.

10. Chung KC, Pillsbury MS, Walters MR, Hayward RA. Reliability and validity testing of the Michigan hand outcomes questionnaire. J Hand Surg Am. 1998;23(4):575-87.

11. Hudak PL, Amadio PC, Bombardier C. Development of an upper extremity outcome measure: the DASH (disabilities of the arm, shoulder and hand) [corrected]. The upper extremity collaborative group (UECG). Am J Ind Med. 1996;29(6):602-8

12. MacDermid JC. Development of a scale for patient rating of wrist pain and disability. J Hand Ther. 1996;9(2):178-83.

13. Metcalf $C$, Adams J, Burridge J, Yule V, Chappell P. A review of clinical upper limb assessments within the framework of the WHO ICF. Musculoskelet Care. 2007:5(3):160-73.

14. Shauver MJ, Chung KC. The Michigan hand outcomes questionnaire after 15 years of field trial. Plast Reconstr Surg. 2013:131(5):779e-87e.

15. Dogu B, Usen A, Kuran B, Yilmaz F, Sirzai H. Comparison of responsiveness of Michigan hand outcomes questionnaire, disabilities of the arm, shoulder and hand questionnaire, and Duruoz hand index in patients with traumatic hand injury. J Back Musculoskelet Rehabil. 2019;32(1):111-7.

16. McMillan CR, Binhammer PA. Which outcome measure is the best? Evaluating responsiveness of the disabilities of the arm, shoulder, and hand questionnaire, the Michigan hand questionnaire and the patient-specific functional scale following hand and wrist surgery. Hand (N Y). 2009:4(3):311-8

17. Dias JJ, Rajan RA, Thompson JR. Which questionnaire is best? The reliability, validity and ease of use of the patient evaluation measure, the disabilities of the arm, shoulder and hand and the Michigan hand outcome measure. J Hand Surg Eur Vol. 2008;33(1):9-17.

18. Poole JL, Gonzales I, Tedesco T. Self-reports of hand function in persons with diabetes. Occup Ther Health Care. 2010;24(3):239-48.

19. Waljee JF, Chung KC, Kim HM, Burns PB, Burke FD, Wilgis EF, et al. Validity and responsiveness of the Michigan hand questionnaire in patients with rheumatoid arthritis: a multicenter, international study. Arthritis Care Res (Hoboken). 2010;62(11):1569-77.

20. Horng YS, Lin MC, Feng CT, Huang $\mathrm{CH}$, Wu HC, Wang JD. Responsiveness of the Michigan hand outcomes questionnaire and the disabilities of the arm, shoulder, and hand questionnaire in patients with hand injury. J Hand Surg Am. 2010;35(3):430-6.

21. Kotsis SV, Lau FH, Chung KC. Responsiveness of the Michigan hand outcomes questionnaire and physical measurements in outcome studies of distal radius fracture treatment. J Hand Surg Am. 2007;32(1):84-90.
22. Chatterjee JS, Price PE. Comparative responsiveness of the Michigan hand outcomes questionnaire and the carpal tunnel questionnaire after carpal tunnel release. J Hand Surg Am. 2009;34(2):273-80.

23. Oksuz C, Akel BS, Oskay D, Leblebicioglu G, Hayran KM. Cross-cultural adaptation, validation, and reliability process of the Michigan hand outcomes questionnaire in a Turkish population. J Hand Surg Am. 2011; 36(3):486-92.

24. Meireles SM, Natour J, Batista DA, Lopes M, Skare TL. Cross-cultural adaptation and validation of the Michigan hand outcomes questionnaire (MHQ) for Brazil: validation study. Sao Paulo Med J. 2014;132(6):339-47.

25. Roh YH, Yang BK, Noh JH, Baek GH, Song CH, Gong HS. Cross-cultural adaptation and validation of the Korean version of the Michigan hand questionnaire. J Hand Surg Am. 2011;36(9):1497-503.

26. Oda T, Abe Y, Katsumi Y, Ohi H, Nakamura T, Inagaki K. Reliability and validity of the Japanese version of the Michigan hand outcomes questionnaire: a comparison with the DASH and SF-36 questionnaires. J Hand Surg Asian Pac Vol. 2016;21(1):72-7.

27. Knobloch K, Kuehn M, Papst S, Kraemer R, Vogt PM. German standardized translation of the michigan hand outcomes questionnaire for patientrelated outcome measurement in Dupuytren disease. Plast Reconstr Surg. 2011:128(1):39e-40e.

28. Ebrahimzadeh MH, Birjandinejad A, Kachooei AR. Cross-cultural adaptation, validation, and reliability of the Michigan hand outcomes questionnaire among Persian population. Hand Surg. 2015;20(1):25-31.

29. Koziej M, Trybus M, Mydlowska A, Salapa K, Gniadek M, Banach M, et al. The polish version of the Michigan hand outcomes questionnaire: cross-cultural adaptation, reliability, construct validity, and measurement error. J Hand Surg Eur Vol. 2018;43(2):199-208.

30. Efanov Jl, Shine JJ, Darwich R, Besner Morin C, Arsenault J, Harris PG, et al. French translation and cross-cultural adaptation of the Michigan hand outcomes questionnaire and the brief Michigan hand outcomes questionnaire. Hand Surg Rehabil. 2018;37(2):86-90.

31. Hulkkonen S, Repo JP, Hakkinen A, Karppinen J, Ryhanen J. Cross-cultural adaptation and validation of the Finnish version of the Michigan hand outcomes questionnaire. Scand J Surg. 2020;109(2):159-65.

32. Dhippayom JP, Trevittaya P, Cheng ASK. Cross-cultural adaptation, validity, and reliability of the patient-rated Michigan hand outcomes questionnaire for Thai patients. Occup Ther Int. 2018;2018:8319875.

33. Beaton DE, Bombardier C, Guillemin F, Ferraz MB. Guidelines for the process of cross-cultural adaptation of self-report measures. Spine (Phila Pa 1976). 2000;25(24):3186-91.

34. Mokkink LB, Terwee CB, Patrick DL, Alonso J, Stratford PW, Knol DL, et al. The COSMIN checklist for assessing the methodological quality of studies on measurement properties of health status measurement instruments: an international Delphi study. Qual Life Res. 2010;19(4):539-49.

35. Cronbach $\amalg$. A case study of the split-half reliability coefficient. J Educ Psychol. 1946:37(8):473-80.

36. Terwee CB, Bot SD, de Boer MR, van der Windt DA, Knol DL, Dekker J, et al. Quality criteria were proposed for measurement properties of health status questionnaires. J Clin Epidemiol. 2007;60(1):34-42.

37. Kirshner B, Guyatt G. A methodological framework for assessing health indices. J Chronic Dis. 1985;38(1):27-36.

38. Tongprasert S, Rapipong J, Buntragulpoontawee M. The cross-cultural adaptation of the DASH questionnaire in Thai (DASH-TH). J Hand Ther. 2014 27(1):49-54.

39. Buntragulpoontawee $M$, Phutrit $S$, Tongprasert $S$, Wongpakaran $T$, Khunachiva J. Construct validity, test-retest reliability and internal consistency of the Thai version of the disabilities of the arm, shoulder and hand questionnaire (DASH-TH) in patients with carpal tunnel syndrome. BMC Res Notes. 2018;11(1):208.

40. Pattanaphesaj J, Thavorncharoensap M. Measurement properties of the EQ5D-5L compared to EQ-5D-3L in the Thai diabetes patients. Health Qual Life Outcomes. 2015;13:14

41. Sakthong P, Sonsa-Ardjit N, Sukarnjanaset P, Munpan W. Psychometric properties of the EQ-5D-5L in Thai patients with chronic diseases. Qual Life Res. 2015:24(12):3015-22.

42. Pattanaphesaj J. Health-related quality of life measure (EQ-5D-5L): measurement property testing and tis preference-based score in Thai population (doctoral dissertion): Mahidol University; 2014.

43. Hinkle DE, Wiersma W, Jurs SG. Applied statistics for the behavioral sciences. 5th ed. Houghton Mifflin: Boston; 1998. 
44. Herdman M, Gudex C, Lloyd A, Janssen M, Kind P, Parkin D, et al. Development and preliminary testing of the new five-level version of EQ-5D (EQ-5D-5L). Qual Life Res. 2011;20(10):1727-36.

45. Devlin NJ, Brooks R. EQ-5D and the EuroQol group: past, present and future Appl Health Econ Health Policy. 2017;15(2):127-37.

46. van Hout B, Janssen MF, Feng YS, Kohlmann T, Busschbach J, Golicki D, et al. Interim scoring for the EQ-5D-5L: mapping the EQ-5D-5L to EQ-5D-3L value sets. Value Health. 2012;15(5):708-15.

47. Hu LBP. Fit indices in covariance structure modeling: sensitivity to under parameterized model misspecification. Psychol Methods. 1998;3(4):424-53.

48. Hu LBP. Cut off criteria for fit indexes in covariance structure analysis: conventional criteria versus new alternatives. Struct Equ Model. 1999;6(1):1-55.

49. Byrne BM. Structural equation modeling with AMOS: basic concepts, applications, and programming. 2nd ed. United States of America: Taylor and Francis Group, LLC; 2010

50. Stratford PW, Binkley JM, Riddle DL. Health status measures: strategies and analytic methods for assessing change scores. Phys Ther. 1996;76(10):1109-23.

51. London DA, Stepan JG, Calfee RP. Determining the Michigan hand outcomes questionnaire minimal clinically important difference by means of three methods. Plast Reconstr Surg. 2014;133(3):616-25.

52. van Kampen DA, Willems WJ, van Beers LW, Castelein RM, Scholtes VA, Terwee CB. Determination and comparison of the smallest detectable change (SDC) and the minimal important change (MIC) of four-shoulder patient-reported outcome measures (PROMs). J Orthop Surg Res. 2013;8:40

53. McHorney CA, Tarlov AR. Individual-patient monitoring in clinical practice: are available health status surveys adequate? Qual Life Res. 1995:4(4):293-307.

54. Mundfrom DJ, Shaw DG, Ke TL. Minimum sample size recommendations for conducting factor analyses. Int J Testing. 2005:5(2):159-68.

55. Marks M, Audige L, Herren DB, Schindele S, Nelissen RG, Vliet Vlieland TP. Measurement properties of the German Michigan hand outcomes questionnaire in patients with trapeziometacarpal osteoarthritis. Arthritis Care Res (Hoboken). 2014;66(2):245-52.

56. van der Giesen FJ, Nelissen RG, Arendzen JH, de Jong Z, Wolterbeek R, Vliet Vlieland TP. Responsiveness of the Michigan hand outcomes questionnaire-Dutch language version in patients with rheumatoid arthritis. Arch Phys Med Rehabil. 2008;89(6):1121-6.

57. Ithanli I, Durmus D, Orekici G. Cultural adaptation of the Michigan hand outcomes questionnaire in patients with carpal tunnel syndrome: a Turkish version study. Chronic Dis Transl Med. 2015:1 (1):42-7.

58. Busuioc SA, Karim M, Efanov Jl, Demers L, Izadpanah A, Harris P, et al. The Michigan hand questionnaire and brief Michigan hand questionnaire were successfully translated to Canadian French. J Hand Ther. 2018;31(4):564-7.

59. Chung BT, Morris SF. Confirmatory factor analysis of the Michigan hand questionnaire. Ann Plast Surg. 2015;74(2):176-81.

60. Schouffoer AA, van der Giesen FJ, Beaart-van de Voorde $L$, Wolterbeek R, Huizinga TW, Vliet Vlieland TP. Validity and responsiveness of the Michigan hand questionnaire in patients with systemic sclerosis. Rheumatology (Oxford). 2016:55(8):1386-93.

61. Wi SM, Gong HS, Bae KJ, Roh YH, Lee YH, Baek GH. Responsiveness of the Korean version of the Michigan hand outcomes questionnaire after carpal tunnel release. Clin Orthop Surg. 2014;6(2):203-7.

\section{Publisher's Note}

Springer Nature remains neutral with regard to jurisdictional claims in published maps and institutional affiliations.

Ready to submit your research? Choose BMC and benefit from:

- fast, convenient online submission

- thorough peer review by experienced researchers in your field

- rapid publication on acceptance

- support for research data, including large and complex data types

- gold Open Access which fosters wider collaboration and increased citations

- maximum visibility for your research: over $100 \mathrm{M}$ website views per year

At BMC, research is always in progress.

Learn more biomedcentral.com/submissions 